\title{
HABITANTES DE LA CIUDAD DEL FUTURO
}

\author{
(HOMO ELUDENS)
}

\author{
Juan Luis Moraza \\ Escultor y Profesor Facultad de Bellas Artes de la Universidad de Vigo \\ https://dx.doi.org/10.12795/astragalo.2017.i23.03
}

"If the present planting of humanity upon Spaceship Earth cannot comprehend this inexorable process and discipline itself to serve exclusively that function of metaphysical mastering of the physical it will be discontinued, and its potential mission in universe will be carried on by the metaphysically endowed capabilities of other beings on other spaceship planets of universe." Buckminster Fuller (1963) Operating Manuals for Spaceship Earth.

En el presente, la tierra es una gota de agua rellena de fuego y rebosante de organismos. Aunque pertenecemos al pequeño $0,001 \%$ de seres pluricelulares, nuestro cuerpo está también plagado de millones de microbios, de los cuales muchos no son pasajeros parásitos, sino aliados esenciales para los procesos orgánicos. El cuerpo humano es en realidad una colonia superpoblada y descentralizada de la que ignoramos casi todo, a pesar de la ilusión gubernamental que nos crea nuestra consciencia. Y es, además, un proceso de intercambios de materia, energía e información. Somos ambiente, sociedad biológica. Y creamos sociedades para vivir, sean clanes, pandillas, aldeas o metrópolis. Los desarrollos técnicos y cooperativos, habrán compensado y retroactivamente habrán incrementado la precariedad orgánica del cuerpo humano, frágil, débil, prematuro... todas nuestras capacidades intelectuales, emocionales y técnicas, son, en realidad, formas invertidas de nuestras incapacidades orgánicas. Pese a nuestra insignificancia biológica, o precisamente por ella, los humanos hemos adquirido un paradójico poder sobre los acontecimientos planetarios. Hemos tenido que reconocer nuestra responsabilidad en la inauguración de un nuevo periodo geológico: el antropoceno $^{1}$ se caracteriza por el impacto de las actividades humanas sobre los ecosistemas humanos. Esta influencia proviene tanto de la explosión demográfica como de las formas de vida que se fueron desarrollando desde que el sapiens monopolizó el destino del planeta: crecimiento exponencial del consumo de energía, de agua, de los transportes de materia y de personas, de las telecomunicaciones, del uso de ferti-

1 Steffen, W.W. Broadgate, L. Deustch, O. Gaffney \& Luwdig, C.: "The Trajectory of the Anthropocene: the Great Acceleration". The Anthropocene Review, 16 de Enero de 2105. 
lizantes, de producción de bienes, la pérdida de biomasa en los océanos y en el manto terráqueo, la destrucción de ecosistemas y la extinción de especies, el debilitamiento de la capa de ozono, junto al aumento de la temperatura de los océanos y sus consecuencias climáticas, y un crecimiento también exponencial de los índices de dióxido de carbono, de metano, de la acidificación del océano, y en general de la degradación de la biosfera. Son las consecuencias del éxito de la vida humana y las causas de su fracaso. Los destinos de la humanidad no habrán sido menos desalentadores que los del planeta que explotan: Los índices de bienestar jamás han sido tan cuantificables, pero, desde luego, no benefician a todo el mundo. El 1\% de los humanos tiene tanto patrimonio como el $99 \%$ restante, y un $20 \%$ de la población consume el $80 \%$ de los recursos planetarios. Incluso en los países más desarrollados, son apreciables altos y crecientes índices de desigualdad social y explotación, una dudosa calidad de la alimentación y del agua, una proliferación de enfermedades provocadas por inventos humanos y sus formas de vida, movimientos de inmigración forzosa. $Y$ los procesos de adaptación a los sistemas artificiales de la vida contemporánea, son mucho más exigentes y tortuosos que los necesarios para adaptarse a un entorno natural. El balance ni siquiera es positivo para el poderoso explotador.

\section{0,1. HOMO ELUDENS, URBE ET ORBE (LA CIUDAD CONTINUA)}

Cuando el sapiens (-165.000) incluyó entre sus capacidades el arte, inauguró la revolución cognitiva del sapiens sapiens (-70.000): activo y contemplativo, juguetón (ludens), versátil (creans), cooperativo (assesor ${ }^{2}$ ) y responsable (suadens), gozaba de una vida opulenta, no idílica, pero sí plausible. Vivía en pequeñas comunidades errantes, recolectando, cazando, imaginando interpretaciones sobre el mundo, y estableciendo correspondencias simbólicas y valores ${ }^{3}$. Para ellos, el planeta era un fascinante y sospechoso ser inconmensurable del que se sentían criaturas, y del que obtenían su saber y su gratitud. Su conciencia de límite era efecto de la fragilidad de su equilibrio dentro de las redes de competitividad y cooperación entre especies. Seguía siendo una más entre ellas.

La riqueza de esa forma de vida, habría permitido una prodigalidad demográfica que conducirá al establecimiento de asentamientos estables, una explotación intensiva de los recursos -que incluye la intensificación productiva mediante la agricultura, la ganadería y la industria-, junto a la necesidad de la acumulación, conservación y defensa de los bienes y del propio territorio. La dieta comenzará entonces a ser menos diversificada, causando nuevas enfermedades, menor tiempo de descanso, mayor la dependencia de factores ambientales...

En ambientes más seguros y previsibles, las capacidades mentales se desenfrenan desvelando sus disposiciones creativas y sus resquicios más oscuros. La consciencia, como una existencia paralela a la vida, acabará polarizando el saber hacia una razón instrumental, conforme la huida de la dificultad se transforma en un impulso de poder sobre lo real, conforme esquiva la deficiencia biológica convirtiéndose en dominio cultural. El sapiens deviene homo

2 Cfr. Castro Nogueira. L., L., M.A. (2008) ¿Quién teme a la naturaleza humana? Madrid. Tecnos.

3 Mithen, S. (1996) Arqueología de la mente. Barcelona. Mondadori. 


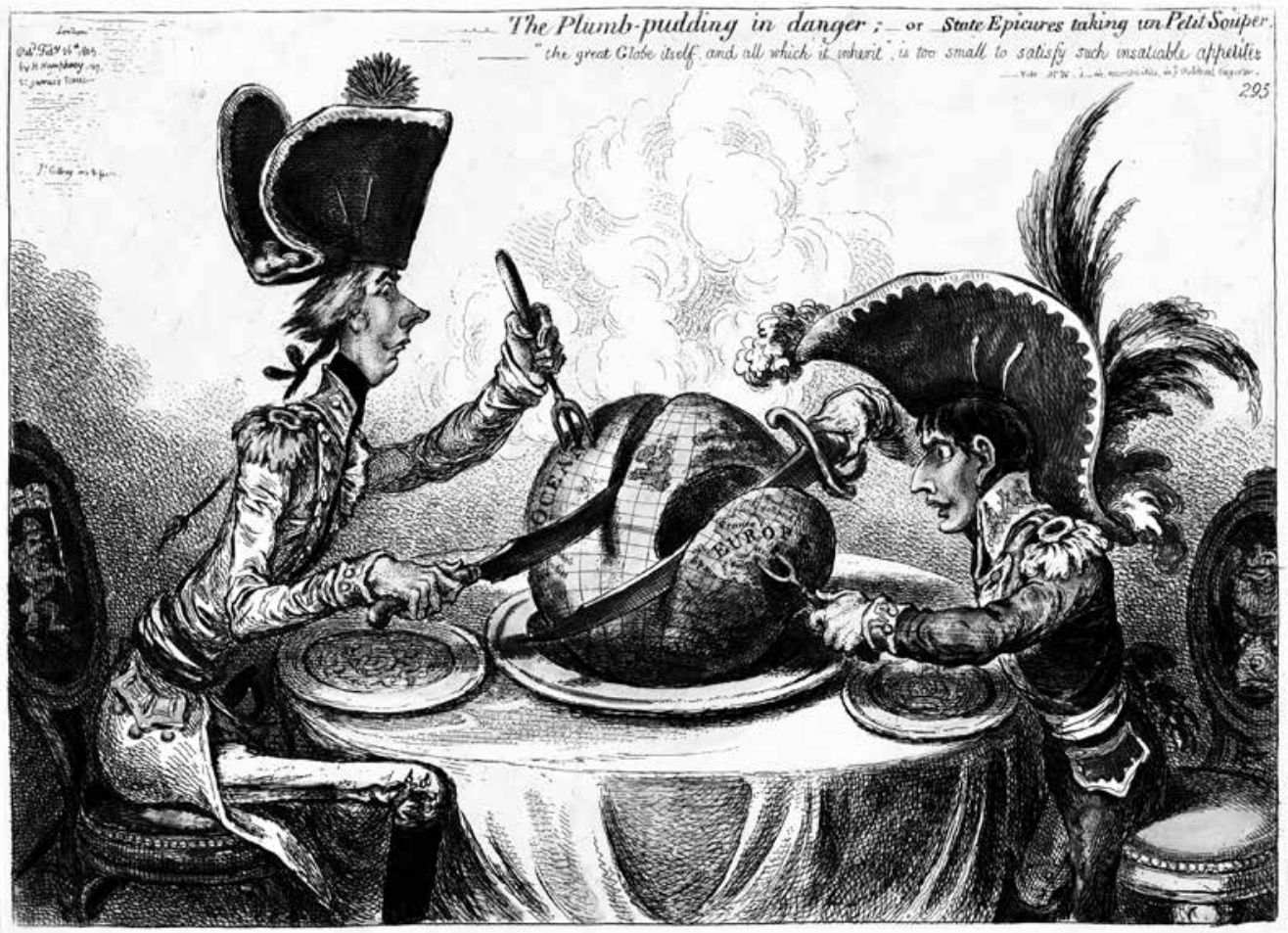

ig. 2. James Gillray (1805) The Plumb Pudding in Danger.

eludens $(-12.000 /+2000)$. El uso (instrumental) y el sentido (simbólico), son dos técnicas contrafactuales ${ }^{4}$ de eludir la precariedad orgánica. Esta involución neolítica inaugura la lógica de la especialización: tanto la percepción como la conducta se parcelan; se produce una desintegración cognitiva que permite un crecimiento funcional de la parte, a costa de un debilitamiento del todo; de las particiones del sistema nervioso surgirá la escisión (science) entre pensar y actuar, creando mundos imaginarios y segregando el habla de la experiencia, y el ser del enser. Y como consecuencia, se intensificará la división del trabajo, la fijación de identidades -de especie, sexo, raza, clase-, la determinación

4 Scarry, E. (1987) The Body in Pain. Oxford University Press de roles sociales estables, incluso hasta convertirlos en hereditarios, y para ello, la institución de sistemas simbólicos que determinen las diferencias y legitimen las jerarquías. Todo ello incrementará el poder de producción y predicción, a cambio de sacrificar la integración del saber, y convertirlo en poder. Por primera vez, armas de guerra, ejércitos, poseedores, vasallajes, trabajos forzados, instrumentalizarán la capacidad de cohesión social del orden simbólico, para organizar las primeras y complejas sociedades preestatales. Así habrá surgido la ciudad, como paradójica antropogénesis del homo eludens (fig. 2).

Desbaratada la eficacia de los ecosistemas del sapiens, la artificialidad de la forma de vida urbana aspira a una restitución integra- 


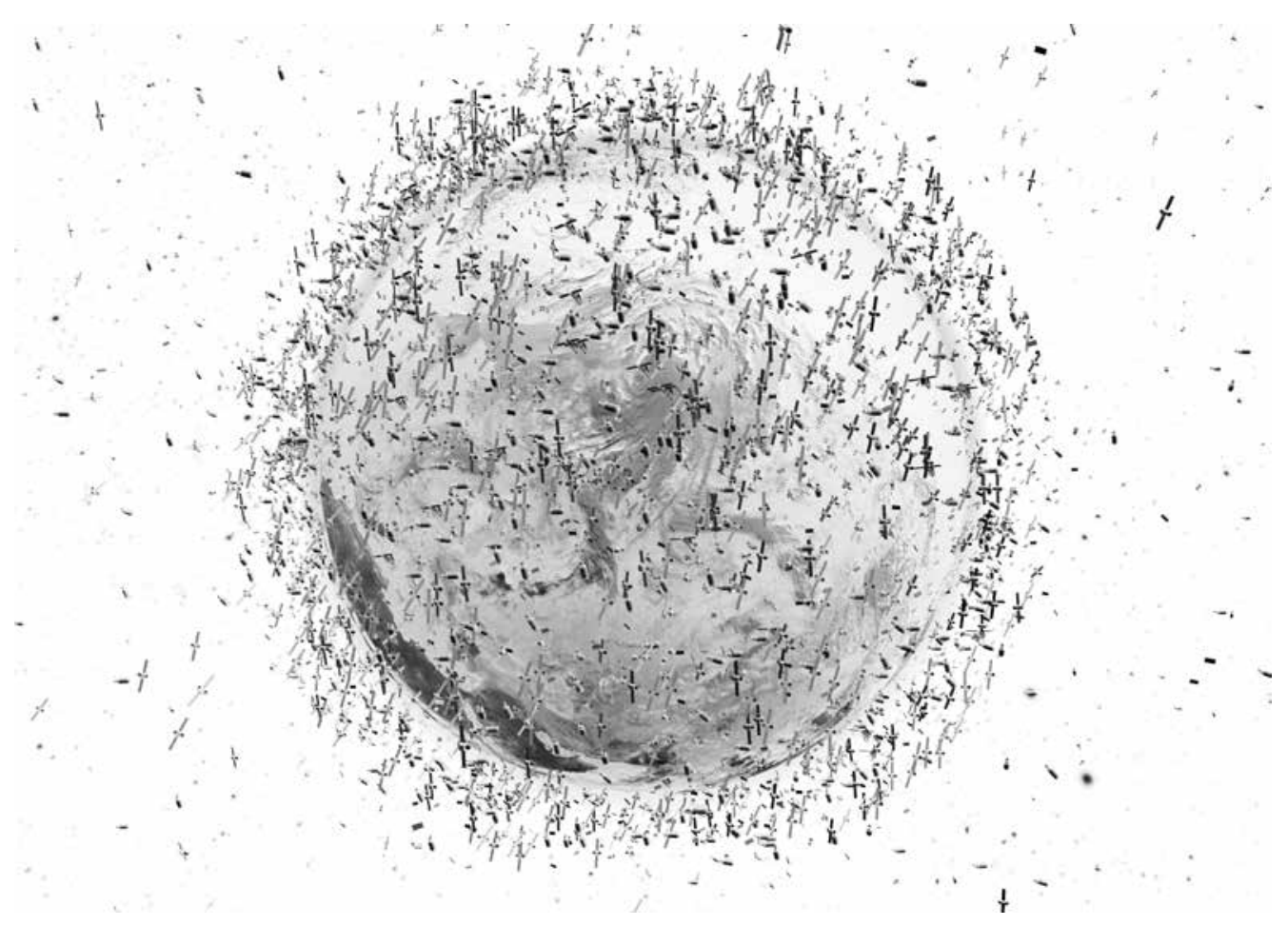

Fig. 1. Representación gráfica de satélites y sus escombros orbitando. Se ha aumentado el tamaño de los satélites para favorecer la visibilidad de su expansión planetaria, pero no se aumentado su número. Créditos: ESA.

dora, pues debe sustituir el orden natural por un sistema creado de interacciones. Desde las primeras ciudades de unos pocos miles de habitantes, hasta las grandes megaciudades de decenas de millones, la ciudad es cuna (civis) de múltiples formas de vida, y red (urbs) de conectividades estables cuya definición territorial excede su perímetro catastral, para incluir todos los flujos de suministros y tránsitos, causa y consecuencia de la especialización funcional, sin los cuales colapsaría de forma inmediata.

La producción de bienes y suministros, las infraestructuras de transporte de personas y de mercancías, las redes de comunicación, los sistemas de gestión y administración no han sido sólo tecnologías imprescindibles para el desarrollo de la ciudad; recíprocamente, la ciudad misma es una condición de existencia para esas tecnologías de gobierno: la construcción de esas infraestructuras y la organización de esas redes, a través las energías, los instrumentos y las relaciones de producción e intensificación del trabajo, así como los mecanismo y rituales de distribución y redistribución, organizan la sociedad en su conjunto. La intensificación de la producción (capitalización de los excedentes), y estimulación de la reproducción (demografía), se determinan y legitiman recíprocamente como vector de desarrollo urbano. El progreso lógico de esta entente es la hiperrealización de la ciudad en una sola ciudad planetaria, expan- 
dida, continua ${ }^{5}$. Desde las sociedades rurales hasta las "sociedades del conocimiento", el tránsito de la revolución agrícola a la revolución tecnocientífica, es continuo. La morfogénesis de la ciudad habrá supuesto un proceso simultáneo de concentración urbana -en ingentes megalópolis-, y de expansión planetaria-en una urbanización extensiva-. La ciudad continua expande su concentración como un moho colonizador y sus redes de interrelación como telarañas cada vez más tupidas (fig. 1). El perfeccionamiento y la expansión universal de los sistemas de conexión y transporte (de materia, energía, información y personas) hacen disminuir la escala del planeta, fortaleciendo el imaginario de una ciudad total. Los satélites y las redes de comunicación y conexión, los asentamientos industriales, los centros de investigación y conservación, la velocidad y eficacia en los desplazamientos no dejan ningún lugar sin cobertura, sin noticias, sin informaciones, sin intereses, como si no existiera un "afuera" de la ciudad, un área del planeta ajeno a esa urbanización extensiva. Incluso las zonas más rurales o los territorios más inhabitables (por su temperatura, presión, altitud o condiciones bioquímicas), contienen núcleos habitacionales $\mathrm{y}$ forman parte de la red de intercambios constituyentes de la ciudad.

Teóricamente, el camino más fácil para alcanzar una nutrición de alta calidad, una vida prolongada, vigorosa y plácida, libre de fatigas y trabajos penosos, no consiste en aumentar la producción, sino en disminuir la población y la dimensión de las comunidades. Pero la intensificación productiva es correlativa al crecimiento

5 Cfr. Bueno, G. (1989). “Teoría general de la ciudad”. Rev. ABACO. No 6 . Oviedo. reproductivo, a la concentración urbana y a la jerarquización social. Cuando las técnicas humanas -agricultura, ganadería e industria- creen crear productos de la nada ${ }^{6}$, más bien explotan el medio a un ritmo superior a la regeneración, incrementando una deuda biológica que irá creciendo exponencialmente conforme se instaura la ciudad planetaria. La explotación intensiva y acelerada, elude la rebiogeneración, la restitución a la naturaleza. Cada mejora instrumental dentro de esta urbanización planetaria habría incentivado una sobrepuja medioambiental y social que conlleva nuevos y crecientes problemas, que conducen inexorablemente al agotamiento de la biomasa y a la disminución de la eficiencia productiva. La Comisión Mundial sobre el Medio Ambiente y el Desarrollo (Comisión Brundtland: ONU, 1987), pensando en la posibilidad de un "desarrollo que asegure las necesidades del presente sin comprometer la capacidad de las futuras generaciones para enfrentarse a sus propias necesidades", definió la sostenibilidad de acuerdo a la articulación entre tres factores: ecológico (preservación medioambiental), económico (progreso económico), y social (Derecho, Justicia y redistribución). Asumir esta noción supondría una transformación profunda de las políticas nacionales, y de las economías internacionales, más allá de soluciones regionales. Pero el discurso sobre el "desarrollo sostenible" no ha sustituido al discurso del desarrollismo, sino que lo ha complementado, no sólo a través de discursos escindidos de las prácticas, convertidos en testimoniales legitimadores, sino también a través de fórmulas de solución parciales, desplazadas a nuevas ecoindustrias tecnológicas, y conver-

6 Cfr. Fukuoka,M. (2011) La revolución de una brizna de paja. Teruel. Ecohabitar. 
tidas en una "estética de la sostenibilidad" a la que se aplican arquitectos y urbanistas. La especialización hace que cada aspecto se trate de forma aislada, como si la producción industrial fuese independiente de la gestión de residuos, como si la macroeconomía financiera fuese inocente respecto a la redistribución social, como si los efectos pudieran tratarse sin ocuparse de sus causas.

Si la ciudad continua es la realización extrema de la forma de vida urbana, se hace cada vez más incuestionable que la ciudad es insostenible. Es la cantidad de vida tanto como el tipo de vida lo que provoca la insostenibilidad medioambiental, económica y social. Es la connivencia entre la estimulación demográfica y el desarrollismo productivo. El homo eludens elude sus responsabilidades sociales, económicas y medioambientales; no se comporta como uno más dentro de la gran sociedad planetaria (gaia); asume el estatus de jefatura, de gestión impune. Es la lógica del plus-valor, que elude la redistribución. Si la economía es la ideología de la ciudad continua es precisamente porque se basa en una distribución (nomos) desigual, diferida indefinidamente, en una eco(a)nomía. Es, en fin, la voluntad de poder, instituida en la ciudad planetaria y su economía financiera. Pero la sostenibilidad de los sistemas físicos sobre los que se organiza la vida humana (sistemas agrarios, industriales, urbanos) depende de la posibilidad que tienen de abastecerse de recursos y de deshacerse de residuos, así como de su capacidad para controlar las pérdidas de calidad (tanto técnica como ambiental y social), aunque la lógica financiera de la ciudad continua se sustenta en la fantasía de un flujo indefinido de recursos e inversiones: en el mundo físico, es inviable la fantasía de un flujo circular en el que la inversión corrige el deterioro ocasionado por el propio sistema que la produce ${ }^{7}$. La economía dineraria existe ya como flujo de capital totalmente independiente del mundo material de los bienes y las propiedades del mundo: existe un flujo dinerario más de cuatro veces superior al valor total del territorio entero del planeta incluyendo todos los bienes materiales, naturales y artificiales que contiene. De hecho, serían necesarios más de siete planetas para mantener las formas de vida de los Emiratos Árabes, seis para las de Estados Unidos, más de dos para las formas de vida europeas, y sólo los países del tercer mundo mantienen formas de vida para las que es necesario menos de un planeta. Aunque la ciudad continua es administrada por una economía imaginaria, sus efectos son reales.

\section{0,01. CIUDADANÍAS (ARQUEOLOGÍA DEL PODER)}

La ciudad ha sido la condensación máxima de las utopías antiguas, clásicas, modernas, y contemporáneas: la fantasía de la cultura frente a la naturaleza, del poder del orden frente al caos, que conecte lo particular con lo universal, de la Razón sobre la barbarie, la ilusión de una socialidad donde conviven intereses en conflicto

Fascinante, terrible, temible, gloriosa, la historia de la ciudad es la historia de la mente humana. Recíprocamente, la psicología humana es la historia de su socialidad, de sus vínculos simbióticos o parasitarios con sus otros. La idea de democracia planteó la cuestión del origen y el fundamento de la ley, inaugurando el espacio propiamente social, ajeno a instancias de legitimación descendentes, sobrenatu-

7 Cfr. Odum, H.T. (1980) Ambiente, energía y sociedad. Barcelona. Blume. 
rales, extrasociales. Pero la institución de la ciudadanía habrá comprometido una forma social sustentada sobre una violencia fundacional, excluyente, mediante un doble discurso: el discurso del derecho sin responsabilidad (autos-tautos), que corresponde al poseedor; y el discurso de la responsabilidad sin derecho, que corresponde al desposeído. Mediante esta razón instrumental, el homo eludens niega las interacciones que le constituyen como sujeto, enfatizando sus atribuciones como artífice; esquiva así su responsabilidad y reduce su autoría a una autoridad técnica sobre su artificio. Pero la autoría (augere) viene definida, precisamente, por el compromiso de respuesta, esto es, por la socialidad. La verdadera condición antropológica de la ciudadanía es una sociedad de autores, una sociedad de socios que gestan y gestionan todo aquello que les compete como ciudadanos.

La polis incluye en su naturaleza negociadora a los ciudadanos "apropiados", tanto humanos (los autóctonos bajo ciertas condiciones de origen, raza, clase, rango)... como a seres no humanos pero sí personales que legitiman esas formas de exclusión (dioses, númenes). La domus incluye bajo su dominio a lo inapropiado y excluido: los seres no humanos y no personales, y seres humanos no autóctonos, bárbaros, víveres-, así como a todo aquello que en lo humano resulta inconveniente...). La vida del enser, la $\cos ^{8}$, es reducida a una forma de existencia servicial, sometida a reglas de acción, a significados. En cuanto tal, el enser es mecanizable, instrumental, sustituible, controlable, comprensible, objeto de conocimiento y de uso. Así, forman parte de la ciudad una población muy numerosa de habitantes sin ciudadanía, ex-

$\mathbf{8}$ Cfr. Latour, B., Weibel, P. (eds). (2005) Atmósferas de la democracia. Berlín. ZKM. propiados de su condición autorial, se aprecian como materia prima, o como obras u obreros, insignificantes, instrumentales, sacrificables.

Para los terrestres no humanos, el desarrollo de la ciudad ha supuesto un proceso intensivo de degradación desde su condición paleolítica divina a su mecanización genética. Queridos o repudiados, protegidos o perseguidos, los habitantes de la ciudad destinados a ser compañeros o materia prima, víveres o plagas, comparten un destino. Todo tipo de organismos se crían, se adiestran, se montan, se purgan, se matan, se confeccionan, se comen, en cantidades ingentes. Y sin ellos, la ciudad humana colapsaría instantáneamente. De acuerdo a estimaciones bajas, 345 millones de animales de granja y 150 millones de peces mueren al día, lo que anualmente supone unas cifras de sacrificios que superan los 180 billones entre aves, bóvidos, pollos, patos, cerdos, conejos, gallinas, pavos, ovejas, cabras, búfalos, caballos, camellos, perros y todo tipo de fauna fluvial y marina... una población estable muy superior a la humana, cuyo destino sólo depende de su utilidad urbana, y de cuya devastación industrializada nos nutrimos.

Cuando el animal humano, sufre una exclusión funcional de ciudadanía, Fig. 3. El índice de felicidad planetaria (Happy Planet Index. New Economics Foundation. NEF) está diseñado para medir el desarrollo de los países en función de la expectativa de vida, la percepción subjetiva de felicidad y el impacto ecológico de sus formas de vida, además del PIB y el IDH de los países, para tomar en cuenta la sostenibilidad, solvencia económica y el estado económico en el que se encuentra cada país. Pero el índice de felicidad en absoluto coincide con la posición económica de los países en el mercado 
internacional. Algunos países tienen un HPI bajo debido a las desigualdades sociales, falta de derechos civiles y presencia de conflictos sociales, deficientes sistemas públicos de sanidad y educación, duras condiciones climáticas, o incluso a una tendencia psicosocial a la baja autoestima, pero también a unas formas de vida que conllevan un impacto ecológico negativo, sin conexión con la naturaleza, con escasos mecanismos de protección medioambiental y con escaso uso de energías renovables. Esto explica que Países bien situados en la economía financiera, como Estados Unidos, compartan calificaciones muy pobres con países de economías depauperadas, como Burundi o Zimbaue. Diez de las once primeras naciones del índice 2009 están en Centroamérica y el Caribe. En los once primeros lugares figuran: Costa Rica, Colombia, Venezuela, República Dominicana, Guatemala, Vietnam, Paraguay, Cuba, El Salvador, Brasil y Honduras.tanto civil (vinculada a la libertad y los derechos de propiedad), como política (derecho al voto y a participación), como social (relacionada con los derechos de bienestar) ${ }^{9}$-, deviene homo sacer ${ }^{10}$. En esa situación de servicio ilimitado, el habitante no puede negarse a ser explotado, debido a amenazas, violencia, coerción, abuso de poder, engaño o presión familiar o cultural condiciones que suelen acompañarse de altos índices de desnutrición e insalubridad. Se estima que más de 2.000 millones de personas viven en una situación de pobreza, y más de 45 millones, bajo condiciones de esclavitud funcional, que incluye tanto trabajos forzados o en condiciones inhumanas,

9 Cfr. Marshall, T.H. (2007) Ciudadanía y clase social. Madrid. Alianza.

10 Cfr. Agamben, G. (2010) Homo sacer. Valencia. Pretextos.
Fig. 3. El índice de felicidad planetaria (Happy Planet Index. New Economics Foundation. NEF) está diseñado para medir el desarrollo de los países en función de la expectativa de vida, la percepción subjetiva de felicidad y el impacto ecológico de sus formas de vida, además del PIB y el IDH de los países, para tomar en cuenta la sostenibilidad, solvencia económica y el estado económico en el que se encuentra cada país. Pero el índice de felicidad en absoluto coincide con la posición económica

de los países en el mercado internacional. Algunos países tienen un HPI bajo debido a las desigualdades sociales, falta de derechos civiles y presencia de conflictos sociales, deficientes sistemas públicos de sanidad y educación, duras condiciones

climáticas, o incluso a una tendencia psicosocial a la baja autoestima, pero también a unas formas de vida que conllevan un impacto ecológico negativo, sin conexión con la naturaleza, con escasos mecanismos de protección medioambiental y con escaso uso de energías renovables. Esto explica que Países bien situados en la economía financiera, como Estados Unidos, compartan calificaciones muy pobres con países de economías

depauperadas, como Burundi o Zimbaue. Diez de las once primeras naciones del índice 2009 están en Centroamérica y el Caribe. En los once primeros lugares figuran: Costa Rica, Colombia, Venezuela, República Dominicana, Guatemala, Vietnam, Paraguay, Cuba, El Salvador, Brasil y Honduras. como matrimonios forzados, incluso compatible con una ciudadanía nominal: pobreza, desempleo e inseguridad social, arbitrariedad penal, discriminación racial, sexual y religiosa, desigualdad de oportunidades educacionales, diferencias de clase...

Para los privilegiados ciudadanos, sus derechos comportan también sometimiento, aunque mucho más suave, a la instrumentalización cívica. El núcleo constituyente de la sociedad urbana es la tensión dinámica entre la ciudadanía - como forma de pertenencia y apropiación-, y la subjetividad inasimilable a ese programa. La sociedad del rendimiento incluye entre sus excluidos a todos los sujetos. El 


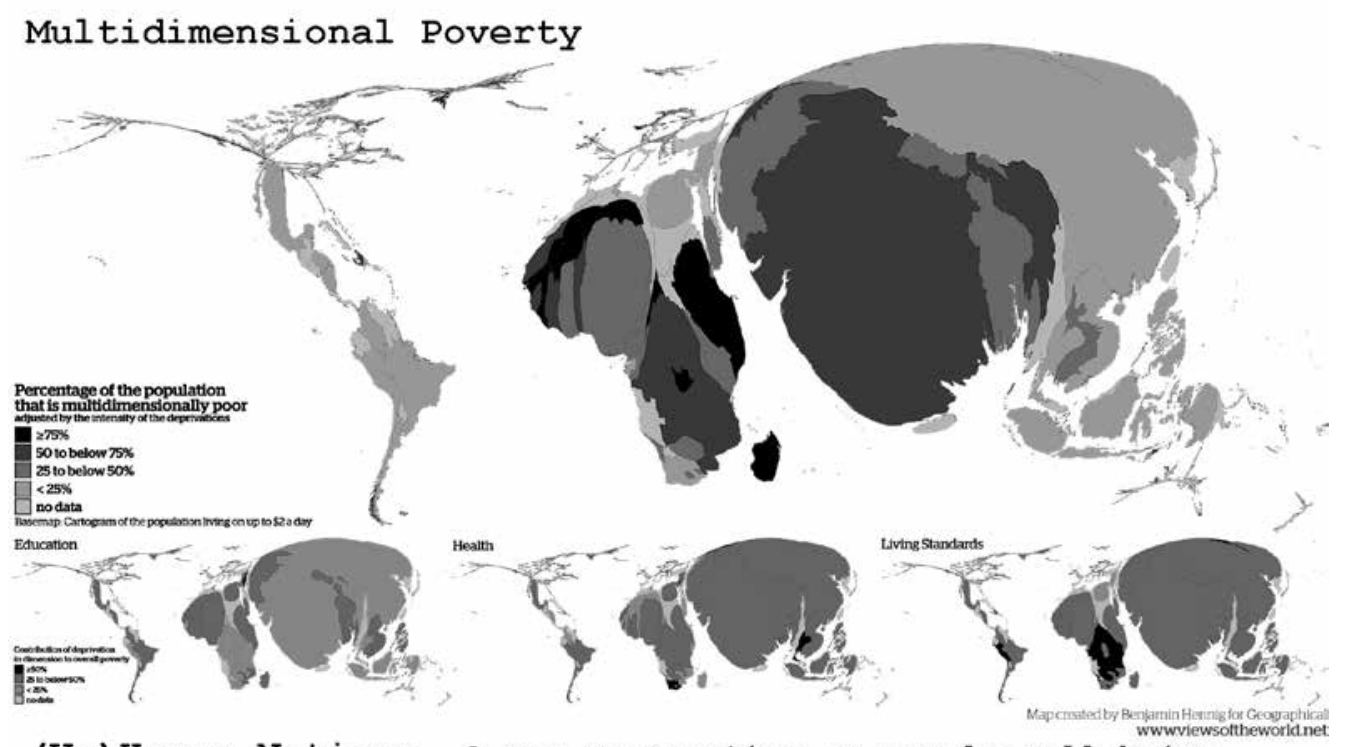

(Un) Happy Nations. A new perspective on people well-being

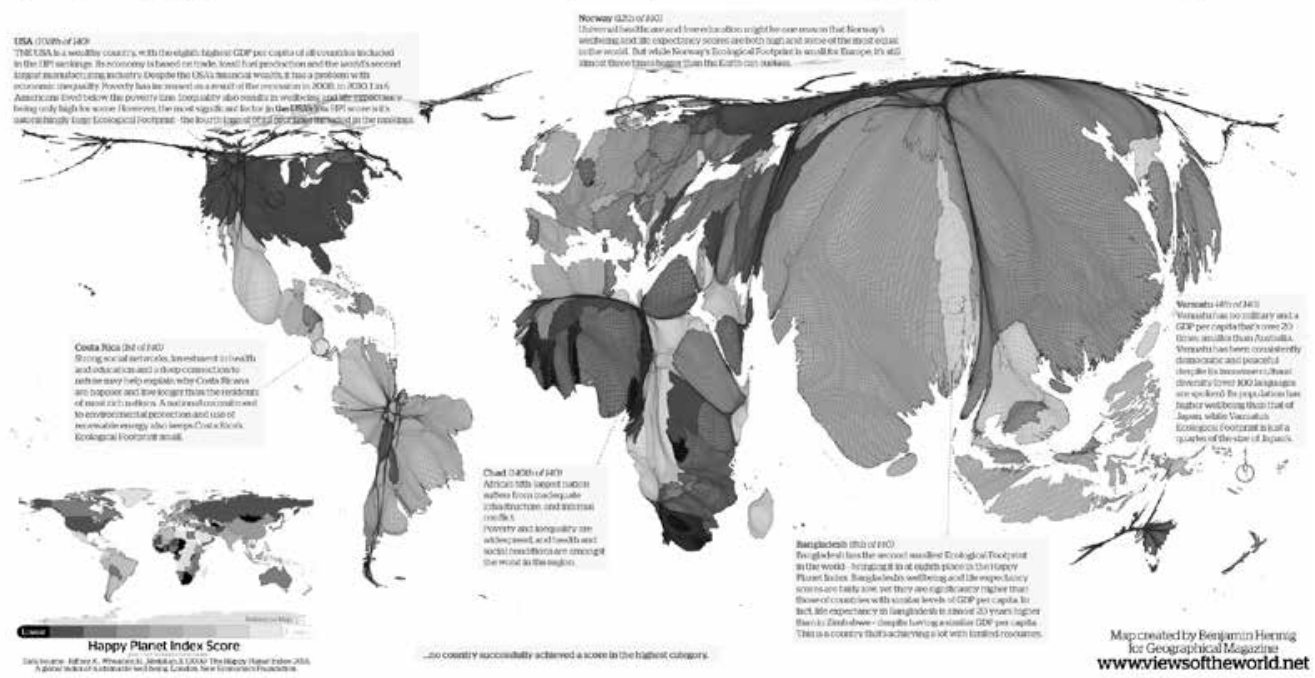

homo eludens, se convierte en su propio objeto de poder, en energía fungible para la gran maquinaria urbana de alto rendimiento.
El zoo humano ${ }^{11}$ es el epítome de la servicialidad: en la ciudad de servicios, todo contribuye al cumplimiento de los designios,

11 Cfr. Morris, D. (1974) El zoo humano. Barcelona. Plaza y Janés 
demandas y deseos de los ciudadanos. Recíprocamente, la vida de los ciudadanos es una contribución al servicio del funcionamiento, el desarrollo y el crecimiento de la ciudad planetaria. El mundo entero se habrá convertido, así, en un recurso que se presupone ilimitado y que existe sólo como objeto de explotación. La ciudad misma, el trabajo y la laboriosidad, el juego, el ocio, los deseos y las motivaciones, el orden y el desorden, la enfermedad y la salud, la vida entera... es entonces un instrumento activo que genera rendimientos financieros; una fuente de plus-valor, un medio y no un fin.

La asimetría social entre los poseedores y los desposeídos no impide sino que confirma la posición inerte que afecta también al poderoso, así como la forma molecular en la que el poder se transmite desde cada individuo, independientemente de su posición (fig. 3). Incluso quienes ocupan lugares más privilegiados dentro de los escalafones políticos, económicos y sociales, están enredados en la lógica instrumental del rendimiento, del trabajo absoluto ${ }^{12}$. Las clases sociales -dominante, trabajadora, ociosa, creativa- siguen existiendo, pero comparten una interiorizada lógica del poder. En cada escalafón, se reproduce fraccionalmente una sumisión al empoderamiento, por lo que la reciprocidad imaginaria entre el poderoso y el desposeído, los exime, simultáneamente, de responsabilidad y de derecho. Es una servicial omnimpotencia compartida.

En la ciudad continua, el poder ya no es personal, ni siquiera estatal, sino corporativo y cibernético. A diferencia de la administración

12 Cfr. Moraza, J.L. (2016). Trabajo absoluto. A Coruña. MAC. pública, tanto las corporaciones como las tecnologías, están exentas de responsabilidades sociales. Ofrecen servicios, pero no de forma desinteresada. A la tecnología se le presupone una neutralidad exenta de responsabilidad, pero convierte al usuario en su instrumento de desarrollo.

La servicialidad de la máquina se extrema en la inteligencia artificial, en la cibernética aplicada al conocimiento y al control sobre la vida humana. Ciertamente, la complejidad de esta ciudad planetaria es causa y efecto de una creciente delegación técnica en manos de sistemas artificiales de computación y de procesamiento que asumen cada vez más parcelas de decisión. Los suplementos artificiales extienden las capacidades humanas al mismo tiempo que las reducen: las formas de organización, cada vez más tecnificadas, desplazan los ámbitos de acción y decisión hacia mecanismos técnicos. Y la tecnificación de los útiles produce una tecnificación de los sujetos. La falta de neutralidad, los límites orgánicos y psíquicos, retroalimentan la justificación de una delegación de la formación de la ciudad en la jurisdicción de lo artificial. De acuerdo a una lógica de conocimiento práctico y eficiencia productiva, la humanidad puede ser considerada incompetente en comparación con la precisión y la pureza de la inteligencia técnica, y por tanto como algo prescindible en el futuro de la ciudad.

Y mientras el Estado aún representa lo público, el carácter servicial de la corporación es privativo, forma parte de una transacción cuya plusvalía siempre escapa a lo ciudadano. El poder corporativo constituye una regresión social, predemocrática, ajena a la representatividad social. Si el homo eludens se hiperrealiza en la corporación, elusiva, supranacional la 


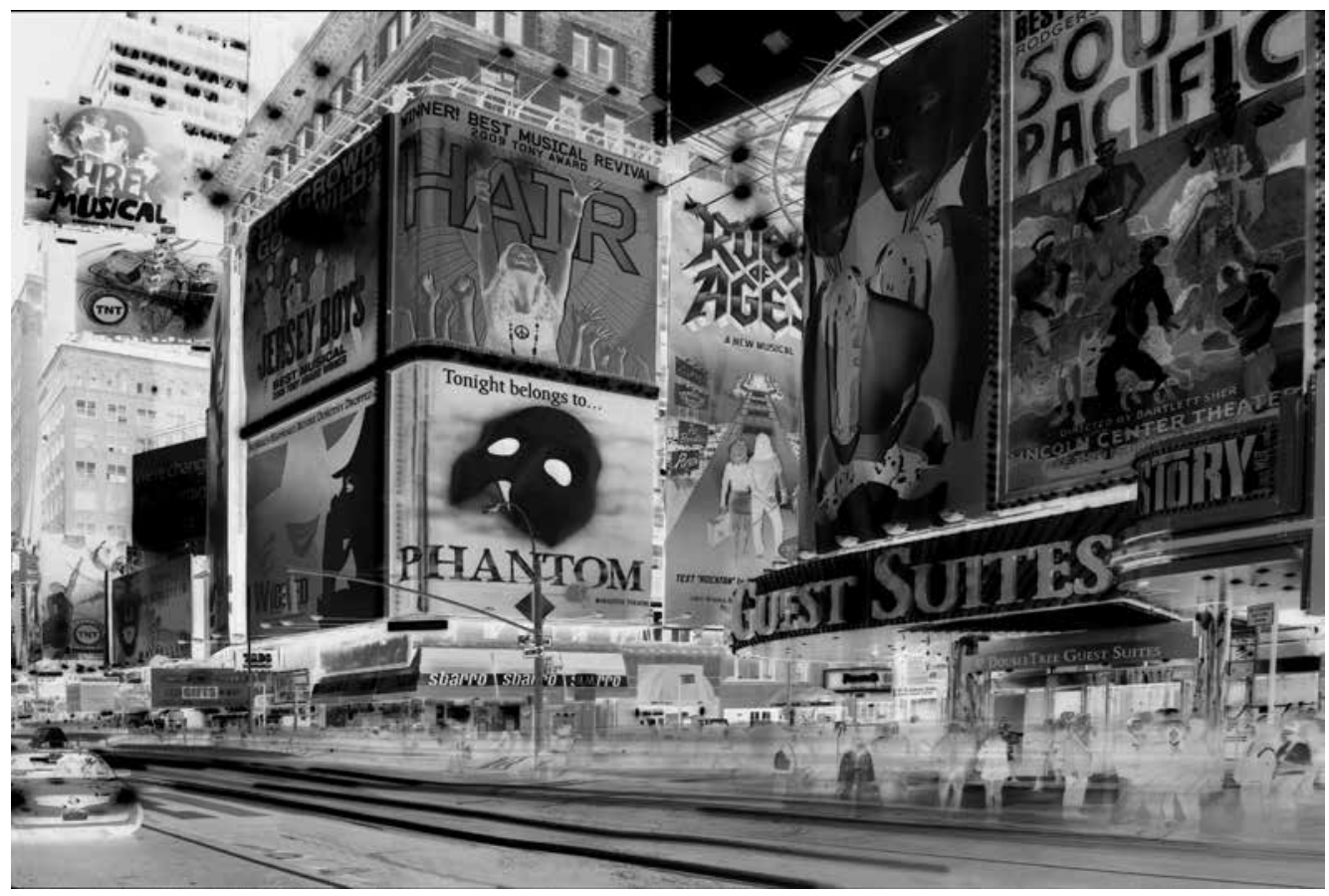

Fig. 4. La ciudad de las ofertas es un gran dispositivo de estimulación que representa el universo imaginario del ciudadano, una autorepresentación social. (Negativo de Nueva York nocturno)

corporación se interioriza fraccionalmente en cada individuo, convertido en una compañía: voluntariamente, cada ciudadano se convierte en una sociedad anónima, convirtiendo su vida en una empresa: amorosa, amistosa, familiar, laboral, intelectual, experiencial El "YO S.A."13, agente de lo propio (idiotes), elude todo lo que esté exento de finalidad, e incluso el ocio, el descanso, la contemplación y el placer, se consideran productivos. Socialmente, los ciudadanos se asimilan a unidades de legitimación, unidades de financiación, unidades de consumo, terminales o nodos de conexión, unidades de formación, unidades de opinión.

13 Cfr. Tom Peters, T. (1997) “The Brand called You”. N.Y. The Fast Company.
No se trata sólo de un poder coactivo, disciplinario, prescriptivo, ejecutado mediante castigos, sanciones y signos disuasorios capaces de provocar miedo e inhibición. Tampoco se trata únicamente de un poder basado en la convicción, implicativo, implantado mediante mitos, creencias, sistemas éticos e ideologías, basados en la persuasión consciente. La ciudad servicial de alto rendimiento se organiza mediante un poder inconsciente, seductor ${ }^{14}$, que se induce mediante reclamos, ofertas, sugerencias, insinuaciones Se trata de una forma de institución elusiva, de una colonización interna de carácter consumatorio, que convierte la espontaneidad

14 Cfr. Fernández, M.L. (1998). Acción y opción: Laberintos. Bilbao. Universidad de Vigo. 
y la voluntad en hábitos convenientes, y generosidad de la oferta en una obligación a recibir. No es un poder autoritario sino inteligente; no doblega la voluntad de los ciudadanos, sino que la atrae. El dominio interiorizado es la escala más dinámica y definitiva del ejercicio de poder.

En realidad, la cultura se comporta como un parásito que coloniza a los inconscientes humanos que la han creado. La adquisición de ciudadanía supone la asunción de un contrato que promete comprensión y convivencia a cambio de comportarse como si el mundo simbólico compartido se correspondiese con lo real, y como si lo imaginario fuese social, a cambio de renunciar a lo inasimilable del sujeto. Mediante la fuerza de los modelos imaginarios y simbólicos que organizan nuestra consciencia y nuestra mente, opera de forma imperceptible bajo el arbitrio de una suspensión voluntaria del descrédito, de modo que los intereses urbanos prevalecen sobre los de sus ciudadanos. La cultura inhibe o estimula ciertos instintos, percepciones, emociones, pensamientos y conductas. Como mecanismo de construcción del imaginario, habrá sido desde sus inicios, un gran mecanismo de producción de opinión, instituyendo las leyes del miedo, la esperanza, y el deseo, no en fases excluyentes sino complementarias, acumulativas, superpuestas. Escenificando allá la majestuosidad y la potestad incontestable de lo absoluto, acullá la fragilidad sentimental de los valores familiares; allá la inquebrantable lógica de la Razón y del Método, acá la voluptuosidad de las utopías de la sensualidad. De hecho, existe una relación proporcional entre la crisis de legitimidad de un sistema de gobierno y su necesidad de sistemas estéticos sensibles a las pasiones, a las debilida- des, a los sueños, las esperanzas y los miedos de la población. Conforme más discutible resulta su legitimidad, tanto más sensuales, dúctiles, plurales y polimorfas serán las estrategias estéticas y publicitarias que promueve...

La "desafección política" y las "políticas de proximidad" se sobrepujan recíprocamente: Conforme mayor es el número de personas que toman conciencia de que forman parte de una sociedad que no les considera socios, y de la insostenibilidad (medioambiental, social y económica) de la formas de vida de la ciudad continua, tanto más poderosos se vuelven los sistemas de inducción de opinión. Se trata de la inversa reciprocidad imaginaria entre lo público y la publicidad. De la tensión entre la libertad de opinión y la asimetría de la influencia.

Los mecanismos ideológicos y estéticos de persuasión, propaganda y seducción, permitirán que la legitimación popular sea plenamente compatible con la persistencia de sistemas despóticos y desigualdades. Desde la Revolución Francesa, la necesidad de creación de opinión fue primero un objetivo político fundamental -desarrollado mediante convincentes estrategias monumentales-, y más tarde en el objeto de un análisis intensivo de la subjetividad y la sociedad, de su valor productivo, y de su fuerza legitimadora. Asumiendo la legitimidad del sujeto como agente de lo social, como autor de la cultura, la cuestión estriba en la posibilidad de condicionar al ciudadano, pues quien posea los medios de producción de opinión pública, detenta, de facto, el poder democrático. Pues en una sociedad basada en una legitimidad popular, la subjetividad es el continente de las exploraciones más incisivas, el gran recurso humano y fuerza de producción. Neurociencia, psicometría, sociometría, demoscopia, merca- 
dotecnia, aspiran a comprender al consumidor, al trabajador, al ciudadano. De ahí que la ciudad continua sea además un gran experimento social, un laboratorio teórico-práctico de investigación destinado a una comprensión minuciosa de la conducta y de la mente humana. Subyace a estos ensayos una teoría mecanicista del sujeto, reducido a una condición reactiva que permita interponer estímulos para crear reflejos condicionados: El homo eludens se convierte así en su propio objeto de estudio y de dominio, convertido en mecanismo, en un complejo amasijo de órganos y sistemas. Y su régimen presupone las emociones como recursos para incrementar la productividad y el rendimiento.

La ciudad, desde sus inicios neolíticos, hasta las metrópolis contemporáneas, ha sido un gran "teatro de procesos inherentes al poder" (Max Weber), una estrategia monumental, psicopolítica ${ }^{15}$, que desarrolla políticas de proximidad, siempre orientadas a la implicación del individuo -sus apetencias, sus peculiaridades, sus deseos, miedos y esperanzas-. Sean agentes comerciales, políticos, o educativos, las estrategias de inducción psicosocial son similares, pues se sustentan en una teoría psicológica que parte de una drástica reducción de la complejidad psíquica. El sujeto analizado es descontextualizado de su vida y recontextualizado en el experimento, o en la consulta; O bien es rastreado en su contexto, mediante poderosos sistemas informáticos implantados en la telaraña de amplitud mundial -redes sociales, correo electrónico, whatsapp, compras virtuales, búsquedas en la nube, etc. En ambas circunstancias, la integridad del sujeto es sometida a particiones funcionales y factoriales. Ello

15 Cfr. Rau.A. (2010) Psychopolitik. Frankfurt. Campus. permite descomponer también la sociedad en particiones conductuales.

En nombre de la seguridad, del conocimiento, o de la noble intención de proporcionar bienestar al ciudadano, desde la segunda guerra mundial, se habrán ensayado numerosos sistemas de análisis psicosociométrico. Desde los clásicos sistemas de clasificación social, sostenidos en datos censales, encuestas o análisis de mercado -ACORN (Richard Webber), PIN (Pinpoint Systems's Mosaic de CCN), Superprofiles (McIntyre Marketing, PRINZM (Claritas Corporation), CLUSTERPLUS (Donnelly Marketing Resarch Bureau)- hasta los Big Data, que cuentan con sistemas de computación que procesan minuto a minuto las búsquedas, respuestas, reflexiones, imágenes, compras, de cientos de millones de personas -SNA (Social Network Analysis), Acxiom (Identity Resolution and People Based Marketing), etc.- se habrán generado modelos de alta resolución sobre la psicología personal y social. Gracias a las tecnologías implantadas en lo cotidiano, nuestra vida se reproduce totalmente en la virtualidad de los datos. Y nuestros hábitos proporcionan una representación muy exacta de nuestra persona, quizá más precisa que la imagen que tenemos de nosotros mismos. Las clasificaciones más simples incluyen factores fácilmente objetivables, como sexo, edad, circunstancias personales como matrimonio, hijos, empleo, datos de consumo, ingresos, clase social, cantidad de miembros de la familia, uso de vehículo lugar donde se vive, personalidad, identificación ideológica y religiosa, valores y actitudes personales y sociales Pero las más sofisticadas, pueden clasificar las sociedades entre "necesitados, supervivientes, luchadores, adaptados, integrados, emprendedores, triunfadores, sociocons- 
cientes, experienciales" (V.A. L.S., Values \& Life Styles. Standford Research Institute); entre "emprendedores, materialistas y hogareños" (Yankelovich, Clandy \& Schulman), entre "sonámbulos, pontificadores, vivaces, virtuosas, lánguidas" (McCann Erikson), ocasionales, habituales, compulsivos, dependientes, ahorradores, buscadores de calidad, devotos de los grandes descuentos, oportunistas, entusiastas, cuidadosos, defensores, exigentes, sofisticados, rutinarios, pensadores, creyentes, cumplidores, afectivos, sensoriales... En realidad, el ser ciudadano comporta una simultaneidad de múltiples formas de vida, una heterogeneidad única. Todas estas identificaciones estratégicas son el correlato de la individualización y la personalización. De hecho, algunas agencias condensan los datos de clasificación en retratos muy específicos, casi biográficos, novelescos, del posible cliente objetivo. Así la agencia Smith Greenland, para una campaña destinada a la promoción del whisky etiqueta negra de Johnnie Walker definió a un virtual Tony Giordano, "un triunfador, un hombre que está en su camino ascendente [] tiene treinta y cuatro años, es abogado, un sujeto para quien los negocios son muy importantes. Quiere mostrar su éxito. Tiene una gran casa, conduce un Mercedes. Viaja en coche a menudo. Es la clase de individuo que si tiene que ir a Minneapolis, pero su hijo actúa en una función, iría, y después telefonearía a su hijo después de la obra." ${ }^{16}$

La publicidad ya no remite a una autorepresentación social (Kant, Habermas). En la ciudad continua, la propaganda ni siquiera necesita mostrarse como publicidad: Los propios

16 Clark, E. (1989) Los creadores de consumo. Buenos Aires. sudamericana: p. 187. Cfr. Cfr. MEYERS, W. (1984) Los creadores de imagen. Barcelona. Planeta sistemas promocionales proporcionan su autocrítica, declarándose culpables de los crímenes de despilfarro económico colosal, de inutilidad social, de falsedad, de persuasión oculta, de catalización de un culto adoración a la necedad, de segregación y de racismo, de pillaje, de crímenes contra la inteligencia, contra la paz civil, contra el lenguaje, contra la creatividad ${ }^{17} \ldots$ pero sólo para justificar una publicidad absoluta, ubicua, indiscernible de la vida. El registro total de la vida biológica (biopoder ${ }^{18}$ ), y personal (psicopolítica ${ }^{19}$ ) confirma que lo imaginario ha llegado al poder. Así, la urbanización planetaria se corresponde con la colonización psíquica. Pues si la publicidad absoluta consuma el dominio en sus formas más poderosas e inconscientes, recíprocamente, el consumo es la realización extrema del dominio. Conforme la vida en su totalidad es reconocida como factor productivo, la ciudad deja de ser un asentamiento humano para ser una factoría lucrativa, una gran empresa dedicada al consumo del mundo.

\section{0,001. SUPLENCIAS (LA CIUDAD DE LA EXPERIENCIA)}

La insostenibilidad de la ciudad continua hace inviable el mantenimiento planetario de un estado de bienestar. Pero debe continuar consiguiendo una implicación cívica para el mantenimiento del sistema urbano, pues la existencia misma es el sector productivo por excelencia. Una vida aceptable en una sociedad de socios, supondría una alimentación suficiente y segu-

17 Cfr. Toscani, O. (2001) Adiós a la publicidad. Barcelona. Omega.

18 Cfr. Foucault, M. (2007), Nacimiento de la biopolítica. FCE. Méjico.

19 Cfr. Han, B.Ch. (2014) Psicopolítica. Barcelona. Herder. 
ra, un trabajo digno, una vivienda estable, una convivencia libre, una participación real en las decisiones que competen a su propio desarrollo Pero lo único que puede ofrecer la ciudad continua es una representación multisensorial del bienestar. La industria de la experiencia ${ }^{20}$ permite un desplazamiento de esos aspectos reales hacia la oferta de experiencias sustitutorias, a través de un servicio extraordinario de goces inducidos. El entretenimiento, la diversificación de los productos de consumo, el universo sensorial de los sabores, los olores; los relatos, lo miedos, las atracciones, las esperanzas suplen las deficiencias de una alimentación no siempre suficiente, ni nutritiva, ni exenta de venenos, unos trabajos no siempre decentes y cada vez más exigentes, unas viviendas no siempre accesibles y cada vez más costosas, y una socialidad que sustituye los vínculos por conexiones, unas formas políticas que degradan la participación a rituales escénicos sin repercusiones Los servicios ya no se dirigen al bienestar objetivo, sino a la inmediata sensación subjetiva de bienestar: experiencias gastronómicas, artísticas, deportivas, lúdicas una "segunda vida"

La fase final de los procesos de implantación urbana supone la interiorización definitiva de los impulsos del homo eludens, la colonización emocional de las experiencias. La vida entera queda subsumida en una oferta de estímulos satisfactorios, de signos de satisfacción. El "estado del bienestar" deja paso a la industria del sentir, que ya sólo debe garantizar intensidades experienciales suficientemente gratificantes cuanto hagan innecesario el bienestar. El efecto narcótico de la industria de

20 Pine, J. and Gilmore, J. (1999) The Experience Economy. Harvard Business School Press, Boston, 1999. la experiencia es tanto más fuerte cuanto se trata de efectos profundamente individuales, incluso aunque se provoquen simultáneamente en miles o millones de individuos de forma instantánea. Las propiedades cuantificables de la calidad del producto y las condiciones mesurables del bienestar - nutrición, salud, salubridad, sanidad, seguridad, descanso, educación-, se suplen en lo inconmensurable de la experiencia -intensidad, fascinación, goce-. Pero son calculables desde la programación estratégica, mediante tecnologías de estimulación. Y sus efectos pueden ser cuantificables en función de los índices de consumo, inducido por factores ajenos a la experiencia misma. Esto permite el florecimiento de una industria de simulacros sensoriales, emocionales y conceptuales, valorables únicamente en función de la satisfacción subjetiva. La ciudad de la experiencia ofrece una realidad aumentada. La vida es suplida por vivencias suficientemente intensas y placenteras, como para compensar cualquier deficiencia en lo real. La vida queda diferida en un universo imaginario-simbólico, tejido de sensaciones, emociones y concepciones respecto a las cuales el individuo se siente una instancia externa a su propia vida. El acceso a lo real del mundo y a lo real del propio sujeto, queda obturado por un imaginario hiperreal, instantáneo, que excede la capacidad sensorial, la resolución, la comprensión y la capacidad de juicio. No se trata de la experiencia vívida que refuerza la subjetividad, sino la inmersión en un imaginario sensible, susceptible, inconstante, influenciable Juegos y juguetes (infantiles y adultos, lúdicos, competitivos, arriesgados o azarosos), dulces y drogas (desde las más clásicas a las más sofisticadas síntesis químicas), y entretenimientos (desde los más mayoritarios a los más elitis- 


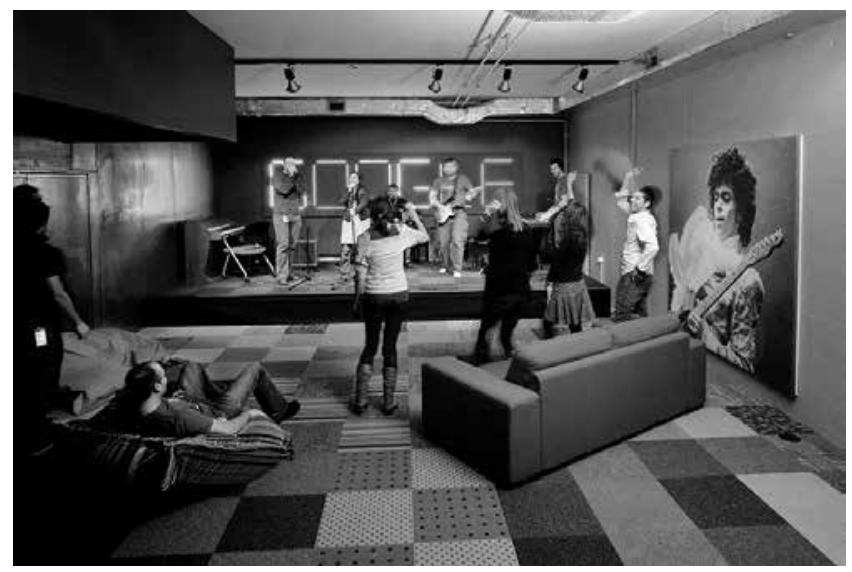

Fig. 4 bis. Los lugares de trabajo pueden convertirse en centros de ocio. Y el ocio de los ejecutivos en una actividad programada por la empresa. Oficinas de Google en Zurich.

tas), distraen al sujeto de sus síntomas, de su realidad. Por procedimientos físicos, químicos o conductuales, eluden lo real de su deseo, de sus causas, de su falta, de todo aquello que la experiencia codificada colma y ocluye. Es el desencadenamiento de un imaginario sin límites, en tanto se experimenta como indiscernible de lo real y de lo simbólico.

La ciudad continua remedia la vida intensificándola para aumentar su valor: Todo lo que contribuya a mejorar los rendimientos y disminuir las deficiencias de atención, constancia, concentración y cansancio propiamente humanas. En el ocio y en el negocio, en el trabajo y en el descanso, se trata de aumentar la productividad, disminuir los índices de error, eludir las emociones que pueden hacer peligrar tomar decisiones difíciles La experiencia ya no es una discontinuidad subjetiva, sino una vivencia inducida. La creación personal de subjetividad, será absorbida en una gran industria de autorrealización imperativa. El buen ciudadano, empresario de su propia existencia, deberá aumentar su rendimiento en todas sus facetas vitales (fig. 4 bis). Así, el culto a la felicidad compulsiva se infiltra en la vida cotidiana tanto como en los planes estratégicos de las empresas, considerada como una exigencia de rendimiento ${ }^{21}$ : Todas las facetas del ser humano, todo tipo de emociones, asociadas a todo tipo de vivencias personales, serán consideradas como susceptibles de mejora, y por lo tanto el individuo podrá someterse al arbitrio y al adiestramiento de expertos, terapeutas y fármacos.

Cada situación vital, cada encrucijada, cada dilema, dispone de su propio tratamiento. Incluso las fricciones con lo real devienen también capitalizables y espectáculos: los trastornos personales, los conflictos sociales y las catástrofes naturales son oportunidades. En la ciudad de la experiencia florecen la industria de la identidad, la industria de la emoción, la industria del desamor, la industria del dolor, la industria del sufrimiento, la industria del riesgo, la industria del instante, la industria del aburrimiento, la industria de la guerra, la industria de la inseguridad, la industria del desastre. La oferta contiene todo lo imaginable, e imagina todo lo contenible. $Y$ el imaginario se estructura de acuerdo a esa oferta extensiva, omniposible. Sin falta, sin responsabilidad, sin exterioridad. Es una ciudad estupefaciente, narcótica, ficticia ${ }^{22}$, su-

21 Cfr. Spicer, A. y Cederström, C. (2010) The Wellness Syndrome. N.Y. Polity.

22 Cfr. Verdú, V. (2003) El estilo del mundo. Barcelona. Anagrama. 
rrealista ${ }^{23}$, psicótica ${ }^{24}$. Estimulante, fascinante, atractiva, en la que todos quieren vivir ${ }^{25}$ al precio que sea, esto es, sin reparar en gastos, en sacrificios personales, corporales, emocionales o ideológicos. Todo es posible, mientras quede alojado en la experiencia diferida: Los conflictos sociales (guerras, altercados) y los conflictos corporales (enfermedades, venenos, muerte), y los conflictos personales (desequilibrios, neurosis, psicosis), se eluden en formas crónicas, diferidas, desplazadas, inapreciables, sublimadas, bien mediante su ocultamiento, o bien por su conversión en espectáculo. No es "el retorno de lo real", sino la conversión de la experiencia traumática en capital. La deuda convierte el mundo en un botín interminable, un paraíso en la tierra en el que, como en unos grandes almacenes, puedes disponer de cualquier bien ...mientras continúes teniendo crédito. Pues la lógica del desplazamiento y la sublimación, en realidad no modifica lo real de los conflictos.

\section{0,0001. DISOCIEDADES (UN PRESENTE SIN AHORA)}

Si el sapiens surgió como consecuencia de una precaria integración cognitiva, el homo eludens, hiperconsciente y servidor de sí mismo, ha devenido un homo resapiens, un resabiado y enrevesado cibernántropo ${ }^{26}$, afectado de una

23 Cfr. Ramirez, J.A. (1983) Edificios y sueños (Ensayos sobre arquitectura y utopía). Universidad de Salamanca.

24 Cfr. Perniola, M. (1997) “¿Hacia un realismo psicótico?”. Rev. Mania: nº 3, 1997. Barcelona: 101-106.

25 Cfr. Florida, R. (2008) Las ciudades creativas. Barcelona. Paidós

26 Cfr. Lefebvre, H. (1980) Hacia el cibernántropo. Barcelona. Gedisa. disociación cognitiva, por una escisión extrema entre los discursos y las acciones, entre las emociones y los pensamientos, entre la percepción y la emoción, entre una experiencia presente y la siguiente. La integración cognitiva que articulaba (ars) las inteligencias natural, social y técnica del sapiens, entremezclando en su forma de sabor ${ }^{27}$, un incipiente conocimiento inteligible con una experiencia sensible. Contenía ya una doble disociación respecto a lo real: el delirio personal de lo imaginario, y el delirio social de lo simbólico. Los sistemas culturales desarrollan, extienden, despliegan, justifican, los sustratos inconscientes, pero también los ocultan, los desplazan, los perturban. Y las tecnologías "extienden" las capacidades sensoras, computacionales y motoras del cuerpo humano. Pero esas extensiones ${ }^{28}$ civilizadas no sustituyen el fondo de barbarie, sino que lo rehúsan y desarrollan.

Somos primitivos de alto artificio. Nuestro cuerpo no sólo contiene millones de microorganismos. Contiene también la historia completa de la evolución. Nuestra experiencia es el resultado combinado y no siempre articulado entre diferentes actividades cerebrales superpuestas que proceden de momentos evolutivos diferentes. El núcleo cortical de nuestro cerebro sería la parte más antigua, similar en sus funciones al de un cerebro reptiliano, incapaz de anticipación, inhabilitado para la memoria, que ofrece una experiencia instantánea, hecha de automatismos relacionados con los aspectos más básicos de la supervivencia -hambre, sed, saciedad, sexualidad, territo-

27 Cfr. Moraza, J.L. (1999) a-S. Arte y saber. San Sebastián. ARTELEKU.

28 Cfr. Hall, Edward T. (1972) La dimensión oculta. Madrid: Sgl. XXI. 
rialidad- una experiencia ávida, radicalmente circunscrita a la inmediatez del instante y a la obtención unilateral de sus impulsos sin ninguna apelación de vínculo social. Alrededor de este cerebro primitivo, se encontraría un "cerebro mamífero", que rige los comportamientos instintivos modificados por la experiencia, la memoria y los sentimientos, el parentesco, etc. tan importantes en establecimiento cultural de la familia, la empatía, el asesoramiento, la cooperación, etc.; Y finalmente, la parte más reciente y fina, llamada el neocortex que está especializado en la invención y la creatividad, en el pensamiento divergente, la disociación y la asociación de los datos de forma diferente y en contextos diferentes a los originales.

Tanto las percepciones como las conductas personales, como las estructuras simbólicas, las conductas culturales, y las formas de socialidad, estarán nutridas por la disociación del este cerebro tríuno ${ }^{29}$, especialmente agravada por el espectacular desarrollo funcional del neocortex asociativo. La creatividad neoténica, infantil, que incorpora esta tendencia disociativa, contribuye a una relativización de todos los impulsos de cohesión, memoria, socialidad y Derecho, toda estructura simbólica, característicos del cerebro mamífero, pero simultáneamente desinhibe el poder pulsional, ávido, amnésico, individual y agresivo, del cerebro reptiliano. Recíprocamente, por influencia del cerebro reptiliano, la creatividad sin límites, convertida en un fin en sí misma, deviene, paradójicamente, una inercia ${ }^{30}$, un automatismo. La ciudad continua es la expresión de la actividad

29 Cfr. MacLean, P.D. (1964). Man and his animal brain. Mod. Med. 32.

30 Cfr. Moraza, J.L. (2012) El arte en la era del capitalismo cognitivo. Centro de Estudios Museo Reina Sofía. funcional de ese paleocerebro ${ }^{31}$, enriquecido espectacularmente por el servicio ultracreativo y prospectivo del "neocortex asociativo". Es la cultura del homo œeconomicus ${ }^{32}$, la "sociedad del conocimiento", en la que el saber mismo se ha convertido en investigación desarrollo e innovación. Es el imperio de la instantaneidad de la experiencia, de la anticipación sin memoria, de la obsolescencia programada, de la divergencia y la transgresión institucionalizada...

En la infinitud interna de un imaginario absoluto, proyectado irracionalmente hacia el futuro, impulsado a considerar sistemática y temerariamente lo bueno como enemigo de lo mejor, nuestros instintos pueden desbocarse en todas las direcciones posibles. Las manías, las particularidades, las apetencias, las perversiones, pueden fluir sin restricciones éticas, ni morales, ni ideológicas, y cumplir sus fines de forma unilateral. Una triple elusión, una destitución de lo simbólico, una oclusión de lo real, y una reclusión en lo imaginario, suponen una fragmentación existencial que desintegra también las diferencias sobre las que se sustentaba la urbanidad clásica y moderna: se vuelven indiscernibles el trabajo y el descanso, el negocio y el ocio, lo urbano de lo rural, la planificación y el acontecimiento, el estado de Derecho y la facticidad, el orden urbano y el desorden, las finanzas y la vivencias, la necesidad y la fortuna, la objetividad y el delirio, la templanza y la pasión, la empatía y la perversión: todas las facetas de la vida, como en la psicología infantil, si-

31 Cfr. Laborit, H. (1971). El hombre y la ciudad. Barcelona. Cairos.

32 Persky, J. (1995) "Retrospectives: The Ethology of Homo Economicus." The Journal of Economic Perspectives, Vol. 9, No. 2: 221-231 


\section{NEOCORTEX ASOCIATIVO}

invención, descontextualización, recomposición, creatividad, riesgos sin cálculos ANTICIPACIÓN SIN MEMORIA, OBSOLESCENCIA PERCIBIDA, DESCONTEXTUALIDAD

\section{CEREBRO MAMÍFERO}

MEMORIA, SOCIALIDAD, CONTEXTUALIDAD comportamientos afectivos

comportamientos institnitvos modificados

por experiencias, sentimientos y asesoramientos

\section{CEREBRO REPTILIANO}

INSTANTÁNEO,

SIN ANTICIPACIÓN,

SIN MEMORIA

conducta gobernanda por instintos

comportamientos repetitivos de

hambre, saciedad, sed

celo, territorialidad, caza,

linaje, jefaturas

\section{CLANES, HORDAS \\ PODER DE HECHO \\ poder coactivo \\ intereses tribales \\ sociedades unánimes, imperios \\ sumision, lucha}

\section{SOCIEDADES INSTITUCIONALES}

\section{ESTADO DE DERECHO}

PODER DE PERSUASIÓN, NEGOCIACIÓN

hábitos, creencias, convicciones, ideologias,

leyes, organizaciones, culturas

sistemas simbólicos, prácticas instituyentes

principios de autoridad, subjetividad intersubjetiva

\section{SOCIEDADES CREATIVAS}

\section{PROGRAMACIÓN ESTRATEGICA}

PODER CORPORATIVO, PODER CIBERNÉTICO, PODER DE SEDUCCIÓN

$\mathrm{I}+\mathrm{D}+\mathrm{i}$, mercadotecnia, destitución simbólica, destitución institucional, contracultura capitalización universal, industrias de la experiencia. destitución subjetiva,

Fig. 5. Bisociación entre las complejidades del cerebro (MacLean) y de la sociedad tríuna. 
multáneamente indiscernibles y disociadas. La gerontocracia de las culturas clásicas deviene paidocracia en las culturas postmodernas.

En la ciudad continua, el sujeto se disocia en una disgregación de experiencias, pulsiones y emociones, que se suceden aisladas, como una serie de momentos especializados; en goces parciales, condenados a la obsolescencia, pues no satisfacen, sino que intensifican y prolongan la tensión nerviosa, provocando una nueva insatisfacción, y por tanto fidelizando el consumo de su objeto. El sujeto de la ciudad absoluta está desconectado de sus síntomas ${ }^{33}$, ya no tiene siquiera indicios sobre lo que le sucede: enredado en las significaciones y usos sociales inducidos, colapsa de forma repentina, sin saber qué le sucede, confiando en uno $\mathrm{u}$ otro tratamiento físico, químico o psicológico. No se trata ya de la división interna del sujeto moderno, entre su fondo inasimilable y sus máscaras sociales. La individualidad se comporta ahora como una carcasa socialmente sólida, que contiene una desintegración interna invertebrada, difusa. El individuo mismo existe recorrido por divisiones desestructurantes que sólo encuentran una solución de continuidad en caparazones identitarios exógenos, elegidos dentro del repertorio de propiedades e identidades a la carta. No es el individuo indiviso, sino el objeto de identificaciones reconocibles, un hiperactivo autosirviente que se emancipa contra sí mismo. La cuestión ya no es la alienación, o la posibilidad de reaccionar activamente contra el imaginario social. Sino más bien de qué forma las sociedades contemporáneas no sólo asi-

33 Cfr. C. Gallano (2002) "Retornos del sujeto del inconsciente en la clínica actual”. Rev. Clínica y Pensamiento. $\mathrm{N}^{\circ} 1$. Madrid. AePCL. milan fácilmente lo inasimilable, sino que de forma inexorable, lo capitalizan, lo convierten en un elemento legitimador y productivo; de qué forma la destitución del imaginario social es sustituido por un imaginario individual; de qué modo, en fin, el "ultraindividualismo" (L. Ferry), o el "superindividualismo" (Bruckner), no suponen en absoluto una afirmación del individuo, sino una constatación de su elusión.

La ciudad continua no estimula una multitud cooperante, sino una agregación de individualidades segregadas, con serias dificultades para el establecimiento de vínculos, sólo conectadas entre sí por significantes externos, por tecnologías de conexión sin implicación, por identificaciones inducidas. Segregado de los demás en sus vínculos, la supresión de la acción social propia de los ciudadanos, hace emerger, cada vez más las formas clásicas de perversión y melancolía, depresión, y ataques de ansiedad, junto a formas extremas de conducta en lo social: De un lado la hipostasía del universo imaginario, en forma de escenificación de lo imaginario en lo real (acting-out); de otro, la emergencia de lo real, sin escena, sin elaboración imaginaria (pasaje al acto).

Empatía, solidaridad, cooperación, surgen puntualmente en situaciones catastróficas, desvelando aún la persistencia de un sustrato social. Pero la vida cotidiana, al degradar la subjetividad, destituye la socialidad, al desconsiderar al ciudadano como socio. La ciudad, sociedad de autores, deviene disociedad de dividuos. En nombre de la abolición de un principio autoridad (autos, autos), se promulgó la destitución de la función autorial (Barthes, Foucault, Bourriaud), pero en la práctica, lo que realmente habrá sido destituido es el principio 
cia creativa de la aceleración, de la velocidad, de la transformación y la subversión. El sentido de una sociedad que se articula alrededor no ya de un replanteamiento de su propio mundo, sino una institucionalizada negación, de una indiscutible resistencia a cualquier estabilidad posible, por muy breve que fuese. De acuerdo a esta lógica de obsolescencia, cualquier fórmula de vínculo social, cualquier sistema simbólico, quedarán instantáneamente obsoletos en la fugacidad del instante. No es ya la programación de la obsolescencia, sino la institucionalización de la imposibilidad social, de la imposibilidad del establecimiento de significaciones, representaciones, objetivos o afectos que son sean inmediatamente objetados. Es la perversión de la moderna "destrucción creativa" (Picasso) -deslegitimadora, desmitificadora, contracultural-, a una postmoderna creatividad destructiva. La ciudad de la obsolescencia social no se articula ya en vínculos, sino en facciones de oposición. El odio inextirpable a la estabilidad es además una resistencia imponderable a la democracia. Interiorizada la lógica del empoderamiento, la demo(a)cracia supone la democratización del absolutismo. En las demo(a)cracias actuales, el poder del pueblo es una máscara social que encubre una legitimidad usurpada por la facticidad de un poder técnico, financiero, burocrático y corporativo, real, indiscutible.

El futuro es, inexorablemente, una anticipación. En todas sus versiones emocionales, esperanza y miedo, ilusión y angustia, imaginamos el futuro en función de nuestra experiencia presente y todas las persistencias del pasado en el presente. El futuro es una forma de vivir el presente ${ }^{34}$, pues el futuro real es

34 Cfr. Maturana, H. y Pörksen, B. (2010) Del ser al hacer. Buenos Aires. Granica. impensable, exterior a lo simbólico. No es que sea inconcebible, es que cualquier anticipación pertenece sólo al presente de la imaginación. El futuro es la quintaesencia del poder del homo eludens, al futuro se confía todo aquello que se rehusa. El resapiens vive en el futuro, desplaza las paradojas, contradicciones y conflictos fuera de su presente, sobrecargando sus deudas -económicas, ecológicas y psicológicas hacia el tercer mundo, y hacia ese "tercer tiempo" de un porvenir incierto. La deuda es la metonimia de lo real a lo imaginario: el plus-valor, el crédito, la obsolescencia, la razón instrumental, la creatividad, el consumo, lo efímero, la utopía ... se fundamentan en un futuro diferido. Planes estratégicos, balances de riesgos, expectativas de crecimiento, programas de investigación, desarrollo e innovación, tecnociencia tienen un valor fundamental en la mente de los contemporáneos, semejante al que habrán tenido las utopías, quimeras, arcadias, providencia, en la mente de los antepasados: de la "civitas dei", a la "ciudad de vacaciones". Tanto la predicción como la programación, son modelos intensificados de nuestras formas de vida.

La lógica de la actualidad elude el presente, al someter cada instante a una obsolescencia contumaz. La actualidad impone un futuro imposible a un presente desvanecido. En nombre de la experiencia de un "aquí y ahora", la actualidad sume la presencialidad en lo imaginario, como un siempre "ni aquí, ni ahora". Es una experiencia sin presente. Pero el futuro no es el porvenir del presente. La cuestión no estriba en la predicción, ni en la producción del futuro, sino en la reconquista del presente.

La ciudad del futuro es un modelo creado por la imaginación de los ciudadanos. Recíprocamente, la imaginación humana soporta su inca- 
pacidad para afrontar la vida mediante modelos

del futuro, viviendo en lo imaginario. Podremos reconocer, entonces, en nuestros modelos de ciudad futura, la imagen reflejada de todas nuestras emociones: vidas hipertecnificadas, rodeadas de sana vegetación, o apestosas en ruinas industriales o cavernas insalubres en desiertos inacabables, configuradas de acuerdo a modelos tectónicos u orgánicos sabiendo que cada modelo es un proyecto político que modifica el presente. Así, podremos formular todo tipo de delirios tecnológicos y utopías sociales, dignas del ficticio arquitecto Sulkas Perkunas ${ }^{35}$, quien propuso ciudades sin casas, otras con un solo edificio, otras, como la ciudad de la igualdad, formadas por miles de casas todas exactamente iguales, ciudades flotantes, submarinas, subterráneas (fig. 6) o invisibles, incluso una ciudad Camposanto, para convivencia de vivos y muertos...
La ciudad continua nos promete aventuras, poder, alegría, crecimiento, transformación de nosotros y del mundo, y que, al mismo tiempo, amenaza con destruir todo lo que tenemos, todo lo que sabemos, todo lo que somos. Pero agazapado tras todas las formas de elusión, bajo todas las prospecciones e instrumentalizaciones, habita una opacidad sobre la que será conveniente ensayar una humanidad del presente para un porvenir que no puede ser codificado. El antropoceno requiere nuestra responsabilidad. Seguramente la vida y la creación nos exija renunciar a la lógica del dominio, a la impostura del plus valor, al mercado de valores, que incrementan sin interrupción una mortífera deuda -biológica, psicológica, social-. Quizá entonces podamos presenciar el presente. Pues no hay destino, sino causas desatendidas.

35 Cfr. G. Pappini (2012) Gog. Madrid. Debolsillo. 


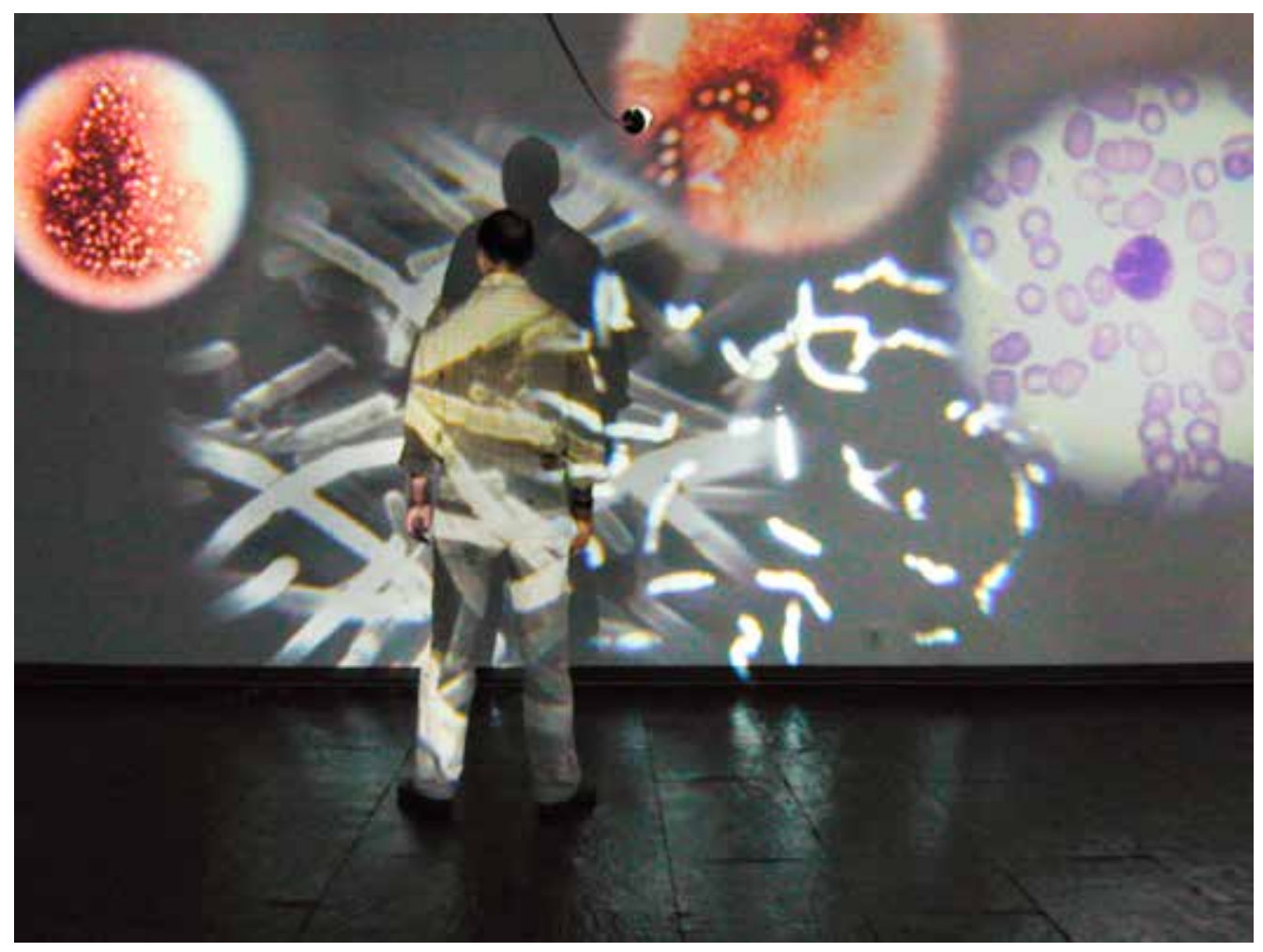

